\title{
Introduction to the Komrower Memorial Lecture 2010
}

\author{
Cornelis Jakobs \\ Published online: 21 April 2011 \\ (C) The Author(s) 2011. This article is published with open access at Springerlink.com
}

Dear members and guests of our Society,

The Komrower lecture was founded by a gift from Mrs Komrower and a bequest from Dr Komrower who died on 11 December 1989.

As is well known to many members of the Society, Dr Komrower performed pioneering work in galactosaemia, homocystinuria and he had a major impact in the early days of newborn screening by introducing PKU screening in Manchester in 1967.

You can find additional information about the life and work of George Komrower in the introduction to the Komrower lecture written by Brian Fowler and published in the JIMD in 1993.

\section{J. Inher. Metab. Dis. 16 (1993) 614-616 Introduction of the Komrower Commemorative Lecture Dr Brian Fowler - Basel, March 1993 $31-12-1911$}

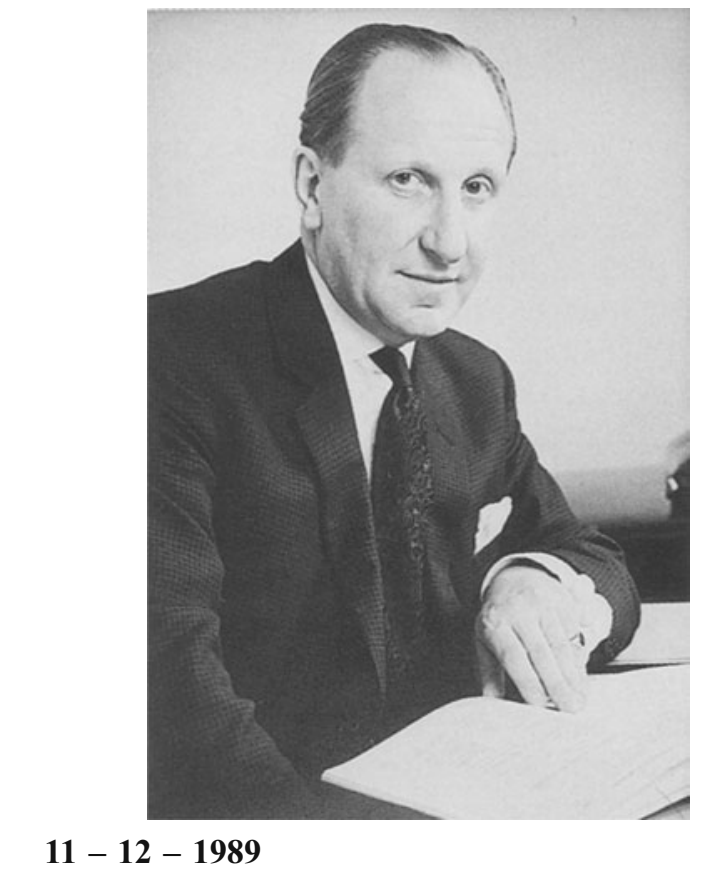

C. Jakobs $(\bowtie)$

VU University Medical Center,

Amsterdam, The Netherlands

e-mail: C.Jakobs@vumc.nl
I would now like to provide some background concerning this years' Komrower Memorial Lecturer: Prof. Bridget Wilcken. The title of her lecture is "Newborn screening: How are we travelling? Where might we get to?"

Bridget Wilcken knew Dr. Komrower personally, and I hope that she will tell about the moments when they have met. They shared research interests in homocystinuria as well as in the new aspects of neonatal screening.

Bridget began her medical career in Edinburgh and during her career she has worked at the Hammersmith and Middlesex Hospitals in London, and spent time in the US, before she went to Sydney, Australia.

From the late 1970s until 2008 she had an university appointment as Clinical Professor in Paediatrics, Western Clinical School, University of Sydney and was Clinical Director of the New South Wales Biochemical Genetics and Newborn Screening Services at The Children's Hospital at Westmead, NSW, Australia.

The Newborn Screening Programme conducts tests on all newborns in New South Wales and the Australian Capital Territory for over 20 metabolic disorders and the Biochemical Genetics Service investigates symptomatic patients from all of NSW. These reference laboratories are the only in New South Wales covering these fields.

She has been seeing metabolic patients at the Children's Hospital since 1984, and has gathered extensive experience in metabolic medicine.

She retired in 2008 from both positions, and currently is running a new adult metabolic service at the adjacent Westmead Hospital.

Prof. Bridget Wilckens early research interests centred around investigations of Homocystinuria. Work linking mild homocystinaemia to the occurrence of vascular disease was carried out early on, and she has been prominently involved in the introduction of betaine as a treatment in pyridoxine-non-responsive cases of homocystinuria.

She also had an early interest in what was then a new field: the fatty acid oxidation disorders, and she adopted this area as a special interest of her laboratory. Her pioneering studies included the first demonstration of the neonatal presentation of fatty acid oxidation disorders, and establishing a link between hepatic pathology in pregnancy 
associated to a fetus affected by long-chain 3-hydroxyacylCoA dehydrogenase deficiency.

And finally: Neonatal screening. In 1981 she was responsible for the introduction in New South Wales of a newborn screening programme for cystic fibrosis and she has an extensive world-wide experience in this area. From the first, this has been a very controversial topic, as firm evidence for benefit from very early diagnosis was lacking. She conducted a study of the efficacy of case-finding by screening, the time and manner of diagnosis before screening, and demonstrated improvement in morbidity and growth in children identified by neonatal screening. This work greatly impacted and enhanced the expansion of $\mathrm{CF}$ screening throughout Australia, and in other parts of the world.

She started an exciting new direction in newborn screening using Tandem mass spectrometry in 1998, being the first publicly funded screening programme to adopt this new screening technology. She was the chief investigator in an Australia-wide study evaluating the reliability, clinical outcomes and economics of tandem mass spectrometry in newborn screening which was reported in the New England Journal of Medicine.

\section{MEMBERSHIP OF LEARNED SOCIETIES}

Bridget was the President of the Human Genetics Society of Australasia (HGSA) from 1997-1999.

She was a founding member of the Australasian Society for Inborn Errors of Metabolism and became president in 1990. The society hosted the IXth International Congress of Inborn Errors of Metabolism (ICIEM) in 2003 in Brisbane, and she was the president of this meeting.

She was a founding member of the International Society for Neonatal Screening in 1988, and in 1991, she was the Chairman of the Organising Committee for the Eighth International Screening Symposium, held in Sydney.

She has been Corresponding Member to the SSIEM Council for many years.

\section{AWARDS, PRIZES}

In 2002 she was awarded the Order of Australia for services to newborn screening. In 2004 she received the Guthrie Medal from the International Society for Neonatal Screening and in 2005 she was appointed to an Honorary Fellowship of the Royal College of Pathologists of Australia.

In summary she has been an advocate for patients for a number of years, as physician, laboratory investigator and political activist, and yet has been able to maintain a very productive research career, with over 140 publications and 8 book chapters.
When I asked her how she looks back to her career she wrote me: I quote

"What I think I should like realised is that I haven't worked all this time. I had virtually 11 years spent largely raising a family, (1960 to 1971) which nobody would do nowadays, and then worked part-time for about 12 years, so my training and experience have been quite spotty. I "retired" in 2008, since when other people's events have conspired to keep me working. And I completed a doctorate only in 2009. So it has been an odd career".

Cornelis Jakobs, September 2010

Chairman SSIEM
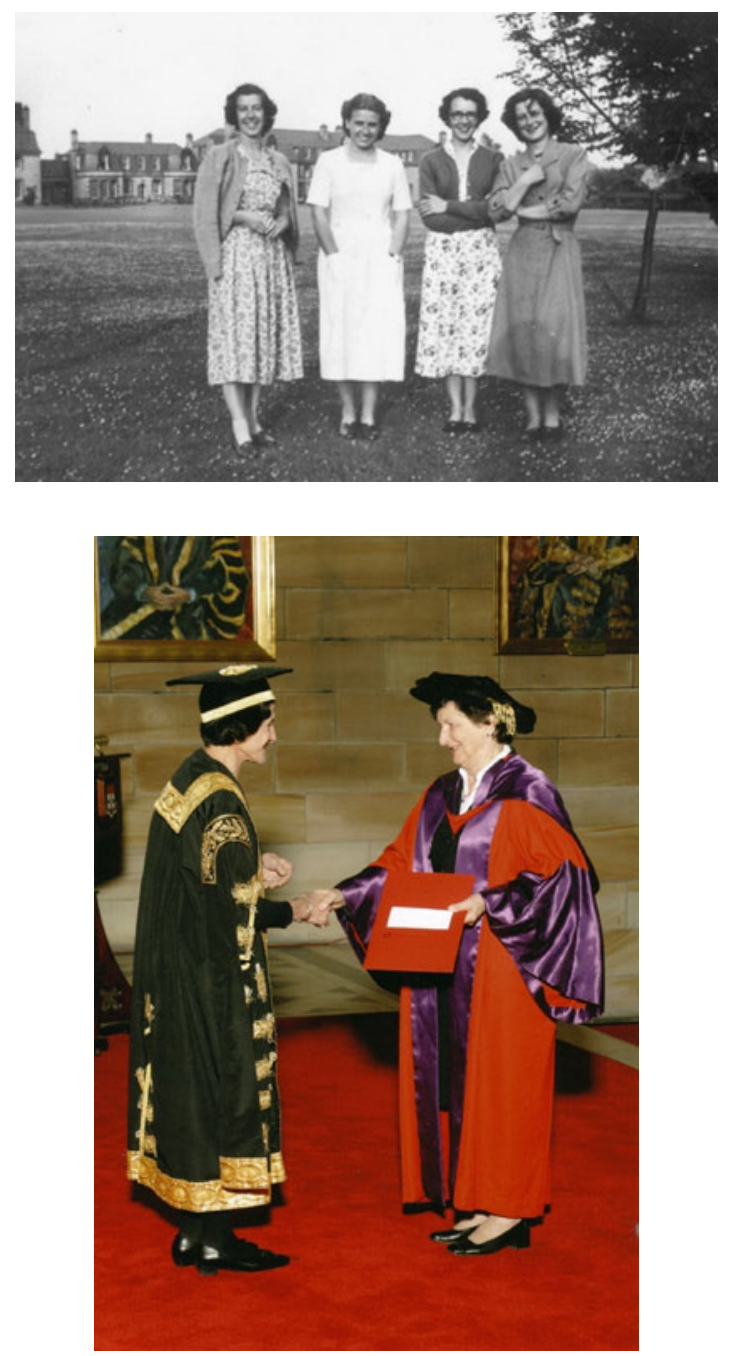

Open Access This article is distributed under the terms of the Creative Commons Attribution Noncommercial License which permits any noncommercial use, distribution, and reproduction in any medium, provided the original author(s) and source are credited. 